\title{
Pretenders to the throne of affordable healthcare?
}

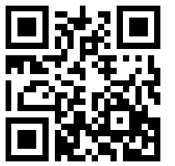

If medical aids are forced to pay the full fee charged by doctors, as the Council for Medical Schemes (CMS) insists they do, then either medical aid subscriptions will become unaffordable or schemes will collapse, denying people their constitutional rights.

This is the view of Dr Humphrey Zokufa of the Board of Healthcare Funders (BHF), which represents over $70 \%$ of existing medical aid schemes. He signalled to Izindaba the BHF's intention to forge ahead in securing either a High Court or Constitutional Court interpretation of the contentious Regulation 8 of the Medical Schemes Act.

Zokufa said his board would be engaging with Dr Aaron Motsoaledi, National Minister of Health, while lobbying all medical schemes to support their court bid. Discovery Health, the largest medical aid administrator, pulled out the BHF several years ago. It disagrees with the BHF's court approach. The BHF wants Regulation 8 either declared 'ultra vires (without legal force) or unconstitutional, arguing that it fails to promote affordability and accessibility to healthcare (Section 27 of the Constitution)'. Regulation 8 itself says simply, medical aid schemes must 'pay in full' the claims of patients, but is silent as to whether this means the maximum rate as defined by each medical scheme's rules, or the actual full service provider fee. The CMS vigorously asserts the latter while medical aids claim the former (which can amount to as little as a quarter of the actual bill although the pay-out ceilings are clearly stated in the rules that members sign up for).

\section{The BHF wants Regulation 8 either declared 'ultra vires (without legal force) or unconstitutional, arguing that it fails to promote affordability and accessibility to healthcare (Section 27 of the Constitution).'}

Zokufa accuses Dr Monwabisis Gantsho, the new CMS chief, of being 'disingenuous' and currying favour with contributors by threatening medical schemes who have ignored CMS letters demanding an

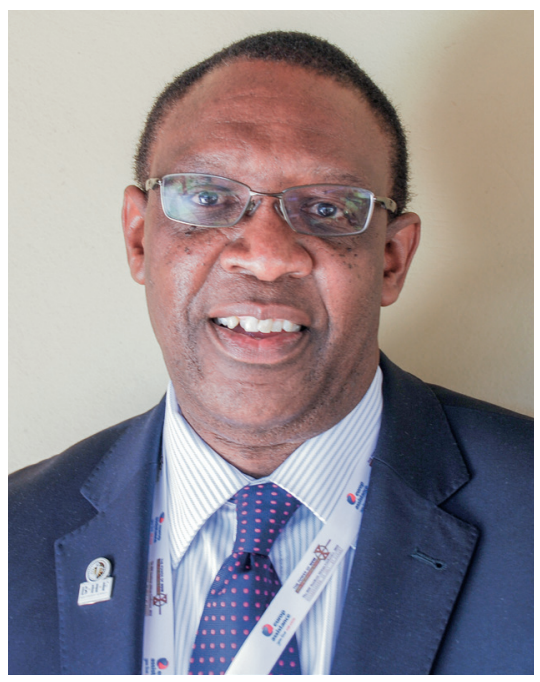

Dr Humphrey Zokufa, Board of Healthcare Funders.

explanation as to why they are ignoring Regulation 8. (In November 2008, the CMS's Appeal Board ruled that service providers must 'pay in full' all invoices related to the costs of providing healthcare services for Prescribed Minimum Benefits (PMBs) without taking the rules of the respective medical scheme into consideration). Zokufa says Gantsho knows that a BHF court action is looming. He sees the CMS broadside as coming close to intimidation of all medical aids, 'the implication being that if you support the BHF in a court case it would amount to frivolous expenditure'. He says the regulator (CMS) is being 'reckless' by demanding the non-productive use of medical aid contributors' money; 'He [Gantsho] must appreciate the negative impact it would have on individual members if their contributions were to increase to make up for those [full] payouts. The schemes are only as strong as their membership base'. Zokufa revealed that the BHF was assiduously gathering data on abuse of the system by anaesthetists, pathologists and surgeons (via several procedures, including caesarean sections) to see what patterns emerged. Gantsho had challenged the BHF to 'produce evidence' of such abuse.

\section{CMS view of Regulation 8 'irrational' - Zokufa}

Zokufa added, 'Basically the way it [the system] works now is totally irrational - you cannot with legislation oblige certain activities [i.e. pay at the provider-charged rates] while opening up a faucet on the other side with no obligations or controls. The BHF has twice asked for exemption from the Competitions Commission Act, which it says 'unfairly' resulted in a 2004 ruling that medical schemes may not collectively bargain with healthcare providers (the commission holding that this was anti-competitive and could lead to price-setting). Zokufa said the impending comprehensive private healthcare probe $^{[1]}$ came after Motsoaledi gave the BHF a lengthy audience on the matter, later approaching the commission and speaking to Dr Ebrahim Patel, his Economic Development cabinet colleague. 'We expect the Commission to do a good job and drill down wherever they can, using their power of subpoena to get to the bottom of anomalies like the sudden CMS annual report surpluses of the last two financial years against a backdrop of deficits for the previous 5 - 10 years.'

The medical aid definition of Regulation 8 will remain the painful everyday reality for medical aid contributors, whether they have expensive comprehensive cover, a simple hospital plan or whether their potentially catastrophic condition qualifies them for PMB medication. The underlying cause of the standoff (besides the unclear regulation) is the absence of any official tariff guidelines, enabling healthcare professionals to charge up to four times the medical aid ceilings. The Health Professions Council of South Africa (HPCSA) whose mission statement is 'to guide the professions and protect the public' had a short-lived shot at proposing 'fair' tariff guidelines last year - eliciting howls of outrage from the medical profession which said they were so low as to be out of touch with reality. The HPCSA is now consulting more widely in an ambitious bid to get multiple role players to agree on what constitutes 'fair' tariff guidelines for private healthcare.

\section{Motsoaledi 'tired' of legal wrangling}

Meanwhile a thoroughly disgruntled and impatient Motsoaledi has vowed to enact legislation to correct the 'untenable' situation, but it could take years. It will probably serve him to await the findings of the subpoena- 
strengthened Competitions Commission enquiry into the private healthcare industry - which only begins in January next year. Meanwhile, it is to the courts we will look, courtesy of the BHF. Whichever court it is, the judges may even decide that it is beyond their ambit to tamper with Parliament's lawmaking powers (i.e. to tinker with faulty legislation). Zokufa says his medical scheme members literally cannot afford to wait for the politicians to amend the law, as ageing populations, more chronic diseases and cancer, costly new treatments and drugs inexorably push healthcare costs higher than the consumer price index. Lined up on the side of the CMS (though some may enter the fray as 'friends of the court') are the South African Medical Association (with 17000 clinician members), the National Minister of Health, the Pharmaceutical Society of South Africa, Mediclinic SA Ltd, the Multiple Sclerosis Society of South Africa and National Renal Care.

\section{Motsoaledi said the CMS ruling gave a perverse incentive to doctors. 'Give me any area of industry where you can just put something on the invoice and say you must pay this?' he asked. \\ He agreed with Zokufa that medical schemes were too heavily regulated, 'while there's nothing on the provider side'.}

Motsoaledi, button-holed by Izindaba at the annual Medical Research Council's awards ceremony on 30 October, professed to still being intent on getting the Competitions Commission to overrule its decade-old ruling that tariff setting was collusive - and getting stakeholders back to the negotiating table. 'I don't believe the tariff setting was collusive. They must just do away with that ruling, it's the quickest and fastest way. Now, whoever puts up suggested guidelines ... you just know there's going to be a court case. There's been court case after court case [since the High Court invalidated the National Health Reference Price List in 2010]. All I kept telling the Competitions Commission is that they made the wrong ruling. It's causing havoc in the [private] healthcare sector, ${ }^{[2]}$ he said. He said treating healthcare as a market commodity (instead of a 'public good') was hugely inappropriate. 'How do you go back when you can't talk

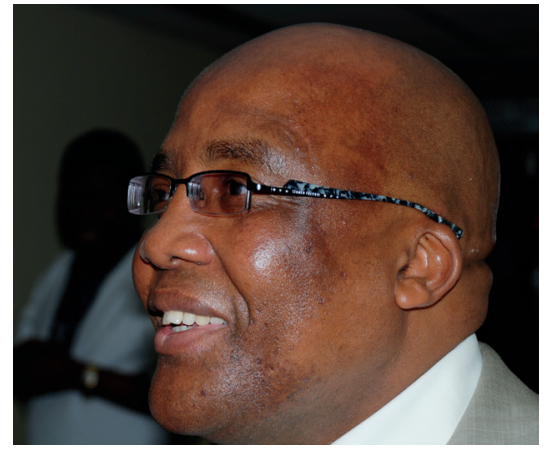

Dr Aaron Motsoaledi, National Minister of Health.

to the stakeholders and say there's a [High Court] ruling here?! That's why I've been chasing the Competitions Commission. In their own wisdom they decided to do the market enquiry, which I welcome, but I must tell you it's not what I asked for.' He said negotiation, while not a perfect mechanism, was far better than the current impasse, and reiterated his call for a pricing commission to provide the government with tariff guidance. Pushed as to when he would be approaching Thembenkosi Bonakele, the then new Acting Competitions Commissioner, he said he had 'only just met him two days ago', but would shortly be 'engaging with him.' 'I'm not in charge of them. Things are very complex and technical but I still believe they can do it [revoke their 10-year-old ruling]. If that happens we can go back to Parliament and show them [his fellow members of Parliament] that they [the legislators] are making life difficult [via the existing Act and Regulation 8].'

\section{Zokufa said his central argument was not about quantum, but survival. If medical schemes went out of business, one by one, millions of current members would suffer an infinitely worse fate than just coughing up ever- increasing annual premiums.}

Motsoaledi said the CMS ruling gave a perverse incentive to doctors. 'Give me any area of industry where you can just put something on the invoice and say you must pay this?' he asked. He agreed with Zokufa that medical schemes were too heavily regulated, 'while there's nothing on the provider side? He also revealed that the white paper would almost certainly push general practitioners (GPs) back into the role of gatekeeper. 'Many specialists will get angry with me, but I don't understand why we've arrived at a situation where patients can just wake up and go to any specialist as a first port of call. In law you don't go to an advocate first, you consult an attorney. If this happened in the legal system it would be hugely expensive. We need to be delegating everything downwards instead of upwards,' he said, citing the success of the Nurse Initiated Management of Antiretroviral Therapy (NIMART). 'I mean, there was no chance of us reaching 2.1 million people if we didn't go to NIMART. He could not see a National Health Insurance working without using GPs as gatekeepers and without nurses becoming more utilitarian.

Zokufa said his central argument was not about quantum, but survival. If medical schemes went out of business, one by one, millions of current members would suffer an infinitely worse fate than just coughing up ever-increasing annual premiums. Two years ago, the BHF made an abortive attempt in the Pretoria High Court to obtain a solid ruling on the meaning of 'pay in full,' but it was thwarted by a technical ruling that it did not represent the majority of medical aid schemes. Almost exactly a year later, a BHF petition to the Supreme Court of Appeal in Bloemfontein was dismissed and the technical Pretoria ruling upheld. ${ }^{[3]}$ Meanwhile, the major role players delivering and regulating private medical schemes continue with the fevered debate - aimed at winning the 'hearts and minds' of their 9 million-strong constituency (17\% of the population), and using broad human rights brush strokes - before our all-encompassing universal health coverage kicks in. The Competition Commission's time-consuming task will probably leave those of us still able to afford medical aid pretty much at sea for at least another two years.

\section{Chris Bateman}

chrisb@hmpg.co.za

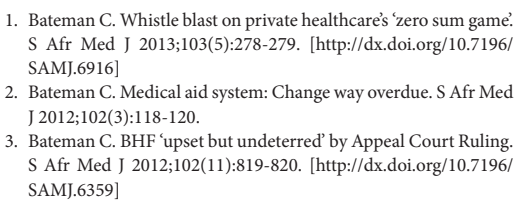

1. Bateman C. Whistle blast on private healthcare's 'zero sum game'. S Afr Med J 2013;103(5):278-279. [http://dx.doi.org/10.7196/ SAMJ.6916]

2. Bateman C. Medical aid system: Change way overdue. S Afr Med J 2012;102(3):118-120.

3. Bateman C. BHF 'upset but undeterred' by Appeal Court Ruling. S Afr Med J 2012;102(11):819-820. [http://dx.doi.org/10.7196/ SAMJ.6359]

S Afr Med J 2013;103(12):885-886

DOI:10.7196/SAMJ.7691 